\title{
In Podospora anserina, protoplasmic incompatibility genes are involved in cell death control via multiple gene interactions
}

\author{
JEAN BERNET \\ Laboratoire de Génétique, allée des Facultés, 33405 Talence, France
}

\begin{abstract}
Protoplasmic incompatibility in Podospora anserina manifests itself as the destruction of cells following anastomosis between hyphae of unlike genotypes. Non-allelic gene interactions between the genes of at least nine loci are involved in this phenomenon. An investigation of five of these loci $(c, d, e, r$ and $v$ ) shows that the corresponding genes are components of a genetic system that controls the growth of mycelium aerial structures (especially protoperithecia and perithecia) via $c / d$, $c / e$ and $r / v$ gene interactions. Perithecium development, after fertilization, depends on the action of the $c$ and $v$ genes in developing perithecia on their corresponding $d / e$ and $r$ genes in the vegetative cells. An analysis of the life span of stationary phase cells showed that the same gene interactions are involved in the premature death of cells which is a response to the genetic conditions that cause perithecium development. These results support the idea that protoplasmic incompatibility is a deviant expression of the cell death associated with the growth of mycelial aerial structures, especially perithecia. This means, in particular, that the degradative activities (especially proteases) associated with protoplasmic incompatibility are responsible for cell death. It is therefore concluded that the genes of the $c-v$ incompatibility loci are part of a multiple gene system. This system regulates, in association with protoperithecium and perithecium development, via the action of two regulatory genes, the production of catabolite activities that convert vegetative cells from quiescence to a source of nutrient available to the female developmental cycle until spore production.
\end{abstract}

Keywords: catabolic activities, cell death, multigenic system, Podospora anserina, protoplasmic incompatibility.

\section{Introduction}

In Podospora anserina, protoperithecia (the female organs) are produced only when the culture medium is practically exhausted (Boucherie \& Bernet, 1980; Durrens \& Bernet, 1985). Thus, when fertilization is delayed (for example for 3-4 days to more than 1 month after protoperithecium production), protoperithecia cannot develop into fertile peritheciaproducing spores by using nutrients in the culture medium. The organism therefore translocates nutrients from vegetative (hyphal) cells. This is consistent with the observation that Podospora perithecia develop concommitantly with the premature death of the neighbouring hyphal cells (Bernet, 1965). Accordingly, when developing perithecia are distributed over all the colony surface, a generalized destruction of mycelium ensues that seems analogous to plant senescence. One particular cell death process, called protoplasmic incompatibility, has been investigated in Podospora to determine whether it might be related to the cell death associated with the female developmental cycle.

Protoplasmic incompatibility designates a process of cell death that ends in protoplasmic extrusion 3-4 h after the anastomosis of hyphae from strains of unlike genotypes (Rizet \& Schecroun, 1959; Bernet, 1965). Allelic or non-allelic gene interactions are responsible for protoplasmic incompatibility (Rizet \& Esser, 1953). In particular, the genes from nine loci are involved in five lethal non-allelic gene interactions (Delettre \& Bernet, 1976). Five of these nine loci have been investigated in greater detail in a study of 16 wild-type isolates (Bernet, 1967). Loci $c, d$ and $e$ determine multiple lethal $C / D$ and $C / E$ interactions due to the 
presence of allelic series, and loci $r$ and $v$ display the $R / V$ interaction which is thermosensitive. Cell destruction associated with protoplasmic incompatibility resulted from the action of two specific proteases in the recombinant lethal strain $R V$ (Bégueret \& Bernet, 1973; Boucherie et al., 1976). Furthermore, despite a severe reduction in overall transcription and translation (Labarère et al., 1974), the synthesis of a specific set of polypeptides was initiated (Boucherie et al., 1981) from pre-existing latent mRNAs and from the transcription of newly induced genes (Barreau, 1983). Genetic studies show that the coupling of two mutations, a recessive in the $\bmod A$ gene and a dominant in $\bmod B$ gene, is necessary to inhibit cell death, irrespective of which non-allelic gene interaction $(C / D, C / E \ldots$ or $R / V$ ) is responsible for protoplasmic incompatibility (Belcour \& Bernet, 1969; Bernet, 1971; Boucherie \& Bernet, 1974).

Three hypotheses have been proposed to explain the biological significance of protoplasmic incompatibility and to account for its widespread occurrence in fungi. In the first, protoplasmic incompatibility is interpreted as a defence mechanism leading to disruption of anastomosis and the protection of individual mycelial clones against invasion by cytoplasm-borne factors such as viruses or suppressive mitochondrial mutants (Caten, 1972). Work with Podospora has led to a second hypothesis. In addition to the disruption of anastomosis, non-allelic incompatibility genes are responsible for the production of sterility barriers between Podospora wild-type isolates (Rizet \& Esser, 1953; Bernet, 1965). It has therefore been postulated (Esser, 1971; Esser \& Blaich, 1973) that non-allelic incompatibility genes are components of a breeding system that has evolved to restrict the outbreeding resulting from the action of the mating-type locus. This presumptive function of incompatibility genes appears unnecessary in Podospora because wild-type isolates are scattered and self-fertile, and because microconidia (the male gametes) are not air-borne. Accordingly, despite the potential action of the mating-type locus, the breeding system of Podospora is similar to that of strictly self-pollinated plant species (Bernet et al., 1960; Bernet, 1965; Belcour, 1985) and thus does not need any additional mechanism to promote inbreeding. The study of the mod mutations that suppress protoplasmic incompatibility in Podospora has led to a hypothesis radically different from that of Esser (1971).

Mutant strains, $\bmod A, \bmod B$ and $\bmod A \bmod B$, have been investigated. Only double mutants $(\bmod A$ $\bmod B$ ) differed from the wild-type strains and by only one feature: a disruption of the production of protoperithecia and their development into fertile perithecia (when protoperithecia were produced under permissive temperature conditions). This result shows, therefore, that protoplasmic incompatibility and protoperithecium and perithecium development share a common biological basis (Boucherie \& Bernet, 1974). Studies of $\bmod A \bmod B$ strains containing various non-lethal combinations of genes $c$ and $d, c$ and $e$ or $r$ and $v$ (several wild-type and mutant alleles have been used) have led to the proposition that $c-v$ genes are also essential for the female developmental cycle via the cumulative actions of $c / d, c / e$ and $r / v$ gene interactions (Boucherie et al., 1976; Boucherie \& Bernet, 1980).

The present work supports the idea that this fundamental function in sexual development is fulfilled by indirect actions of $c-v$ and mod genes. Indeed, it is shown that the $c-v$ genes are responsible for actions specific to hyphal cells that are necessary for protoperithecium and perithecium development and result in the death of hyphal cells.

\section{Materials and methods}

Podospora anserina is fundamentally a heterothallic ascomycete. However, production of normally binucleate ascospores containing nuclei of two mating

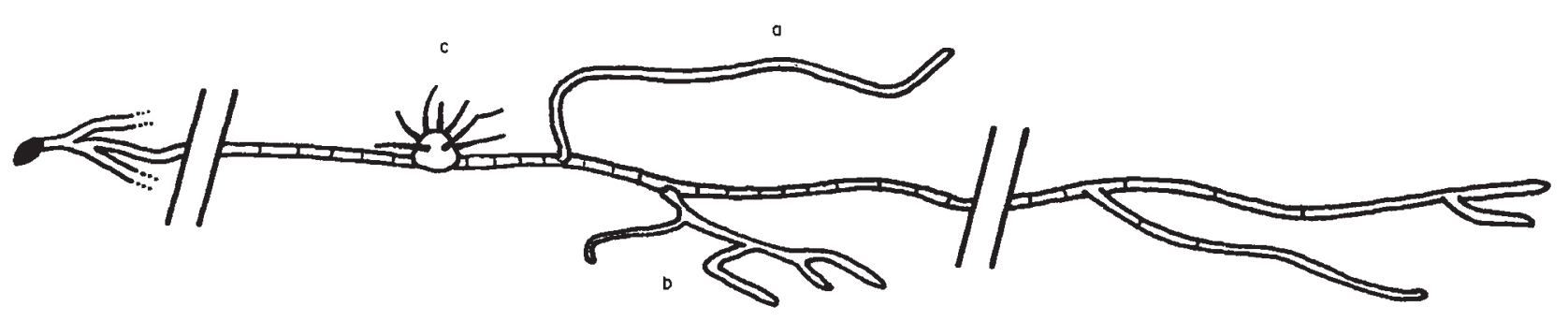

Fig. 1 Growth and differentiation in Podospora. The hyphal cells of leading hyphae have three developmental alternatives: aerial hyphae (a), secondary ramifications $(\mathrm{b})$, and later, following growth completion at growth substrate boundaries, protoperithecia (c). 
types results in the self-fertile heterokaryotic $(+/-)$ mycelia that occur naturally (Ames, 1934; Rizet \& Engelman, 1949). Occasional uninucleate ascospores produce self-sterile $(+$ or -$)$ strains which are used in this work. Growth of the vegetative mycelium by hyphae elongation and branching is due to apical cells. After being shifted to quiescence (Durrens \& Bernet, $1982,1985)$, the hyphal cells are a source of three developmental alternatives (Fig. 1): (i) aerial hyphae, (ii) secondary ramifications (i.e. distorted and slow growing hyphae) and, (iii) if colony growth is stopped at the edge of the culture substrate, then the protoperithecia that support the female cycle until ascospore production. Protoperithecia and perithecia develop outside the growth substrate like aerial hyphae.

\section{Culture medium}

This has been described previously by Esser (1974). In the two media used, the carbon source was the limiting nutrient (Durrens, 1984). Culture on a corn meal extract solid medium allowed the production of protoperithecia and individual perithecia were observed. A synthetic medium (Bernet, 1986) was used as a liquid culture.

\section{Incompatibility genes and mutations}

Lower case letters designate the genes of the $c, d, e, r$ and $v$ loci when they are not involved in lethal gene combinations (wild-type or viable recombinant $c d$, $c e$ and $r v$ genotypes $\rangle$. Allelic series were found at the $c, d$ and $e$ loci, which give rise to several $C / D$ and $C / E$ lethal interactions (Bernet, 1967): thus, $c(A), d(A)$ and $e(A)$ designate alleles of the $(\mathrm{A})$ wild-type isolate, whereas $c(o), d(o)$ and $e(o)$ indicate mutations that inactivate $c, d$ and $e$ genes (Boucherie \& Bernet, 1980). Two wild-type alleles $(R / r, V / V 1)$ have been identified at the $r$ and $v$ loci. Wild-type strain genotypes were $r V$ and $R V 1$ and recombinants were lethal $(R V)$ or viable $(r V 1)$.

\section{ModA modB strain}

Screening for $\bmod A$ and $\bmod B$ mutations was based upon growth restoration of lethal self-lysing strains $C D, C E$ or $R V . \bmod A$ mutations are recessive and modB mutations dominant (Bernet et al., 1973). The female fertility of the double mutant $\bmod A \bmod B$, used in this work, is low (never more than 25 per cent of wild-type fertility) and is thermosensitive (temperatures above $28^{\circ} \mathrm{C}$ being non-permissive). The female fertility of $\bmod A \bmod B$ strains depends on the temperature between 15 and $26^{\circ} \mathrm{C}$, and on gene combina- tions at the $c-v$ loci (Boucherie \& Bernet, 1980). Conversely, wild-type strains $\left(\bmod A^{+} \operatorname{modB} B^{+}\right)$are fully female fertile between 16 and $34^{\circ} \mathrm{C}$.

\section{Mosaic cultures for the determination of the genetic control of perithecium development}

To obtain a clear delimitation of the mycelium of each strain in mixed cultures, one strain (the 'protoperithecial strain') was cultured on solid medium and the second (the 'mycelial strain'), of the same mating type, on a cellophane disk ( $3 \mathrm{~cm}$ in diameter) covered with a layer of culture medium. Both strains were cultured at $16^{\circ} \mathrm{C}$, a temperature permissive for protoperithecium production in all strains of $\bmod A \bmod B$ genotype used in these experiments. When the mycelium had grown to cover the cellophane disks, they were moved onto arrested stationary cultures of the 'protoperithecial' strain. Hyphae from the 'mycelial' strain developed at the edge of the cellophane disks and rapidly fused with the hyphal cells of the 'protoperithecial' strain. These anastomoses did not give rise to heterokaryotic areas as Podospora nuclei do not migrate (BeissonSchecroun, 1962; Bernet, 1965). Cultures were fertilized after protoperithecium production with microconidia from a strain of the opposite mating type and then incubated at a temperature non-permissive for the development of the perithecia of the 'protoperithecial' strain $\left(20\right.$ or $26^{\circ} \mathrm{C}$ according to $c-v$ genotypes). On this strain, perithecia developed essentially from the protoperithecia situated around the margin of the cellophane disks (1-8 $\mathrm{mm}$ outside), which indicates that perithecium development depends on hyphal interconnections between 'protoperithecial' and 'mycelial' strains. To confirm that the 'protoperithecial' strain was the female parent, specific gene markers of the protoperithecial strain were tested using a sample of fertile perithecia.

\section{Dry weight measurements for the determination of cell life span}

One thousand millilitre Roux bottles containing 100 $\mathrm{ml}$ of liquid culture medium were inoculated with hyphal fragments (about 2500 per flask). The cultures were incubated at 20 or $26^{\circ} \mathrm{C}$ (according to $c-v$ genotypes) without shaking. The mycelia were harvested at different times and were dried at $60^{\circ} \mathrm{C}$ for $48 \mathrm{~h}$ in a dessicator before weighing. Although variations in the level of inoculum only affect growth phase and not maximum dry weight production, data were from three independent experiments that involve two cultures each. 
Table 1 Perithecial development by complementation in genetic mosaic cultures

\begin{tabular}{|c|c|c|c|c|}
\hline \multirow[b]{2}{*}{ Expt } & \multicolumn{2}{|c|}{ Mycelial strain } & \multicolumn{2}{|c|}{ Protoperithecial strain* } \\
\hline & Genotypes & Fertility $\dagger$ & Genotypes & $\begin{array}{l}\text { Production of } \\
\text { fertile perithecia }\end{array}$ \\
\hline A & wild-type $(\bmod A$ or $\bmod B)$ & Fertile & $\bmod A \bmod B$ & + \\
\hline B & wild-type $(B 2)$ & Fertile & $\bmod A \bmod B$ & - \\
\hline $\mathrm{C}$ & $\bmod F$ & Sterile & $\bmod A \bmod B$ & - \\
\hline D & modE & Fertile & $\bmod A \bmod B$ & + \\
\hline $\mathrm{E}$ & $\bmod A \bmod B \operatorname{Vrc}(A) d(A) e(A)$ & Fertile $\left(24^{\circ} \mathrm{C}\right)$ & $\bmod A \bmod B \operatorname{Vrc}(A) d(o) e(o)$ & + \\
\hline $\mathrm{F}$ & $\bmod A \bmod B \operatorname{Vrc}(A) d(A) e(A)$ & Fertile $\left(24^{\circ} \mathrm{C}\right)$ & $\bmod A \bmod B \operatorname{Vrc}(o) d(A) e(A)$ & - \\
\hline G & $\bmod A \bmod B \operatorname{Vrc}(o) d(A) e(A)$ & Sterile $\left(24^{\circ} \mathrm{C}\right)$ & $\bmod A \bmod B \operatorname{Vrc}(A) d(o) e(o)$ & + \\
\hline $\mathrm{H}$ & $\bmod A \bmod B \operatorname{Vrc}(A) d(o) e(o)$ & Sterile $\left(24^{\circ} \mathrm{C}\right)$ & $\bmod A \bmod B \operatorname{Vr} c(o) d(A) e(A)$ & - \\
\hline I & $\bmod A \bmod B c(A) d(o) e(o) V 1 r$ & Fertile $\left(20^{\circ} \mathrm{C}\right)$ & $\bmod A \bmod B c(A) d(o) e(o) V 1 R$ & + \\
\hline $\mathbf{J}$ & $\bmod A \bmod B c(A) d(o) e(o) V 1 r$ & Fertile $\left(20^{\circ} \mathrm{C}\right)$ & $\bmod A \bmod B c(A) d(o) e(o) \mathrm{Vr}$ & - \\
\hline K & $\bmod A \bmod B c(A) d(o) e(o) V 1 R$ & Sterile $\left(20^{\circ} \mathrm{C}\right)$ & $\bmod A \bmod B c(A) d(o) e(o) V 1 R$ & + \\
\hline $\mathrm{L}$ & $\bmod A \bmod B c(A) d(o) e(o) \mathrm{Vr}$ & Sterile $\left(20^{\circ} \mathrm{C}\right)$ & $\bmod A \bmod B c(A) d(o) e(o) V 1 R$ & + \\
\hline
\end{tabular}

*'Protoperithecial' strains were grown at permissive temperature to produce protoperithecia and, after fertilization, under nonpermissive conditions to test complementation with the 'mycelial' strains via the production of fertile perithecia. $\nmid$ Definitions for female sterility/fertility and temperature conditions are from Boucherie \& Bernet (1980).

\section{Results}

\section{Genetic control of the growth of aerial mycelium structures}

Previous results (Boucherie et al., 1976; Boucherie \& Bernet, 1980) have shown that $\bmod A \bmod B$ strains are female sterile or partially female fertile according to temperature and gene combinations at the $c-v$ loci (relevant examples are given in Table 1, first column). $\bmod A \bmod B$ cultures were also free of aerial hyphae under non-permissive conditions for protoperithecium production. Other Podospora mutant strains that are unable to produce protoperithecia and aerial hyphae have previously been described (Durrens \& Bernet, $1982,1985)$. These mutants were also defective for the production of secondary ramifications and when grown on cellophane disks placed onto solid culture medium, they only developed on the upper surface of cellophane disks due to their inability to produce secondary ramifications (Durrens \& Bernet, 1982, 1985). The production of secondary ramifications was investigated in $\bmod A \bmod B$ strains by culture on the disks $(10 \mathrm{~cm}$ in diameter $)$ deposited on solid culture medium. Removal of the cellophane disks that support growing $\bmod A \bmod B$ cultures revealed mycelial invasion of the culture medium after 3 days of culture. This result indicates that production of secondary ramifications in $\operatorname{modAmodB}$ strains is wild-type and thus that these strains differ from the mutants previously described. Consequently, $\bmod A \bmod B$ mutations do not suppress production of all derivative hyphal cells, as originally suspected (Labarère \& Bernet, 1979), but only inhibit the growth of those mycelial products that develop outside the growth substrate (aerial hyphae and protoperithecia).

In Podospora, strains that carry mutations of two loci (incA or incB) differ from wild-type by unscheduled aerial development of hyphae at colony boundaries (the edge of Petri dishes or mycelial confluence). This is a consequence of the disruption of an apical cell-specific, pheromonal growth control (Bernet, 1986, 1988). Triple mutants $\bmod A \operatorname{modB}$ inc $A$ (or inc $B$ ), were constructed. Their phenotypes were similar to those of $\bmod A \bmod B$ strains, which indicates that $\bmod A \bmod B$ mutations inhibited the aerial development of apical cells specific to the inc mutations.

A second experiment confirmed the inability of $\bmod A \bmod B$ strains to develop any aerial mycelium. In this experiment, the culture medium was removed from 1 to $2 \mathrm{~mm}$ ahead of the edge of developing colonies (wild-type or $\bmod A \bmod B$ ). Hyphae of wild-type cultures passed beyond the limit of the culture substrate and continued to grow for almost 3 days to produce aerial filaments of $12-15 \mathrm{~mm}$ in length. In $\bmod A \bmod B$ cultures, the hyphae that grew outside the growth substrate were stopped at a reduced final length that depended on the $c-v$ genotype (for instance $3 \mathrm{~mm}$ for $c(A) d(o) e(o) r V$ and $8 \mathrm{~mm}$ for $c(A) d(A) e(A)$ 
$r V 1$ genotypes). Implants were taken from inside stationary mycelia, known to be starved of a carbon source (Durrens, 1984), and were deposited on a glass plate. The implants from wild-type cultures produced hyphae that grew up to $4 \mathrm{~mm}$ above the glass plate. Production of hyphae from $\operatorname{modAmodB}$ implants was retarded and the filaments grew slowly and were no longer than $200-400 \mu \mathrm{m}$.

These results confirm that $\bmod A \bmod B$ strains are defective in a function that is essential for the development of mycelium normally growing, or forced to grow, outside the culture substrate. The conclusion that $\bmod A \bmod B$ strains are unable to support the development of protoperithecia and aerial hyphae and not their initiation is confirmed by the observation that $\bmod A \bmod B$ strains grown under almost non-permissive temperature conditions contain protoperithecia arrested in development and presumptive aborted aerial hyphae.

\section{Autonomous and non-autonomous actions of the $c-v$ genes on perithecium development}

Previous work, based upon the study of heterokaryotic strains, showed that the inhibitory action of $\bmod A$ $\bmod B$ mutations on perithecium development was not perithecium-autonomous. This result led to the presumption that $\bmod A$ and $\bmod B$ acted in hyphal cells to affect perithecium development (Boucherie \& Bernet, 1980). As $c$ and $d, c$ and $e$, or $r$ and $v$ gene interactions were involved in the development of the perithecia of $\operatorname{modAmodB}$ strains (Boucherie \& Bernet, $1980)$, genetic mosaic cultures were constructed to determine whether the action of the $c-v$ genes was perithecium-autonomous or not, as assessed by complementation between genetic components. In these mosaic cultures, the development of protoperithecia into perithecia was analysed in $\bmod A \operatorname{modB}$ strains designated 'protoperithecial' strains. The other strain in each experiment ('the mycelial' strain) contained the genes to be investigated for complementarity in perithecium development (via $c / d, c / e$ and $r / v$ interactions) with the $c-v$ genes of the protoperithecial strain.

Protoperithecia of 'protoperithecial' $\bmod A \bmod B$ cultures developed into fertile perithecia when the mycelial strain was wild-type, $\bmod A$ or $\bmod B$ irrespective of the alleles at the $c-v$ loci (Table 1, Expt A), which confirms that $\bmod A$ and $\bmod B$ were not perithecium-autonomous genes. In contrast, no significant perithecium development was observed when the wild-type 'mycelial' strain contained $B 2$, a gene that determines protoplasmic incompatibility (whose consequence is anastomosis disruption) through allelic gene interaction $(B 1 / B 2)$ with the $B 1$ gene common to all 'protoperithecial' strains (Table 1, Expt B). Nondevelopment of perithecia, consequent to a $B 1 / B 2$ interaction, indicated that hyphal continuity between 'mycelial' and 'protoperithecial' strains through anastomoses was essential for perithecium development in the $\bmod A \bmod B$ 'protoperithecial' strain.

The genetic conditions required for perithecium development were investigated when both the 'mycelial' and 'protoperithecial' strains were $\bmod A$ modB. Previous results (Boucherie \& Bernet, 1980) have shown that a homokaryotic strain of genotype $c(A) d(A) e(A) r v \bmod A \bmod B$ was female fertile at a temperature lower than $25^{\circ} \mathrm{C}$ whereas otherwise identical strains containing mutations $c(o)$ or $d(o) e(o)$ were completely female sterile at the same temperature. The experiments described here (Table 1, Expts $\mathrm{E}-\mathrm{H}$ ) indicate that certain genetic conditions need to be fulfilled at the $c, d$ and $e$ loci for perithecial development. The presence of the $c(A)$ allele in the "protoperithecial' strain and the $d(A)$ and $e(A)$ alleles in the 'mycelial' strain results in production of fertile perithecia (Table 1, Expt G). The reverse genotypes ['mycelial' strain $c(A)$, 'protoperithecial' strain $d(A)$ $e(A)]$ do not give rise to fertile perithecia (Table 1, Expt H). Previous results (Boucherie \& Bernet, 1980) have also shown that $\bmod A \bmod B$ strains defective in $c(A) / d(A)$ and $c(A) / e(A)$ interactions $[c(o)$ or $d(o)$ $e(o)$ genotypes] were female fertile under the double condition of a temperature lower than $21^{\circ} \mathrm{C}$, together with the presence of $r$ and $V 1$ alleles at $r$ and $v$ loci (the other two possible viable genotypes $r V$ and $R V l$ were female sterile). Present results (Table 1, Expts I-L) show that perithecia could develop if $r$ and $V l$ genes are complemented by the presence of the $r$ gene in the 'mycelial' strain and the V1 gene in the 'protoperithecial' strain (expt L).

The results suggest that for each gene interaction $(c)$ $d, c / e$ and $r / v)$ one of each pair of gene products is synthesized in the vegetative cells $(d, e$ and $r)$ and the other ( $c$ and $v$ ) in the developing perithecia (or proximal hyphal cells). As the regulatory genes $\bmod A$ and $\operatorname{modB}$ are not perithecium-autonomous (Boucherie \& Bernet, 1980), it appears that perithecia develop as a consequence of the action of the $c-v$ genes on the $\bmod A$ and $\bmod B$ genes of the hyphal cells; an action required throughout the female developmental cycle (proto- and perithecia). This result is consistent with the idea that the $c-v$ and mod genes might be responsible for the production of nutrients for perithecium development via destruction of hyphal cell material. Therefore, the possibility was examined that the action of $\bmod$ and $c-v$ genes may itself result in the premature death of hyphal cells. 


\section{Quiescence, survival and death of vegetative cells}

The most satisfactory method to assess the life span of filamentous fungal cells is to culture the organism in liquid medium and determine the time course of dry weight production (Durrens, 1983, 1984). All the cells in a liquid medium culture are exposed to identical nutritional conditions (permissive and then nonpermissive for growth). It is therefore possible to show whether susceptibility to nutrient starvation is the only factor that determines cell life span. Furthermore, as liquid medium cultures do not produce protoperithecia, any reduction in cell survival due to the $\bmod$ and $c-v$ genes would indicate that cell death is a direct consequence of the action of these genes and not a secondary effect of perithecium development.

In Podospora, hyphal cells become quiescent (i.e. resistant to nutrient starvation) when the carbon source is the limiting nutrient and the carbon source is glucose (Durrens \& Bernet, 1985). Wild-type and $\bmod A \bmod B$ homokaryotic $(+$ or -$)$ strains were cultured in limiting glucose medium. The survival of $\bmod A \operatorname{modB}$ cells was indistinguishable from that of wild-type cells (Fig. 2a). Thus, female sterility of $\bmod A \bmod B$ cultures was not the result of a premature death of hyphal cells.

As a + / - mating type allele interaction between protoperithecia and microconidia induces perithecium development and, consequently the premature death of the hyphal cells, the cell life span of $+/-$ heterokaryotic cultures was examined. Wild-type self-fertile $(+/-)$ mycelia from the germination of binucleate spores were grown in liquid medium. Potentially selffertile mycelial cells had a shorter life span than (Fig. $2 \mathrm{~b})+$ or - cells. As cultures in liquid medium do not produce protoperithecia, this observation indicated that $+1-$ mating type interaction was active in the absence of fertilization and resulted in the premature death of vegetative cells. To investigate the action of $c$ $v$ and mod genes, other heterokaryotic $(+/-)$ strains of $\bmod A \bmod B$ genotype, permissive or non-permissive for protoperithecium production and perithecial development, were cultured in liquid medium. Cell survival of $+1-\bmod A \bmod B$ strains containing $c-v$ gene combinations non-permissive for perithecium

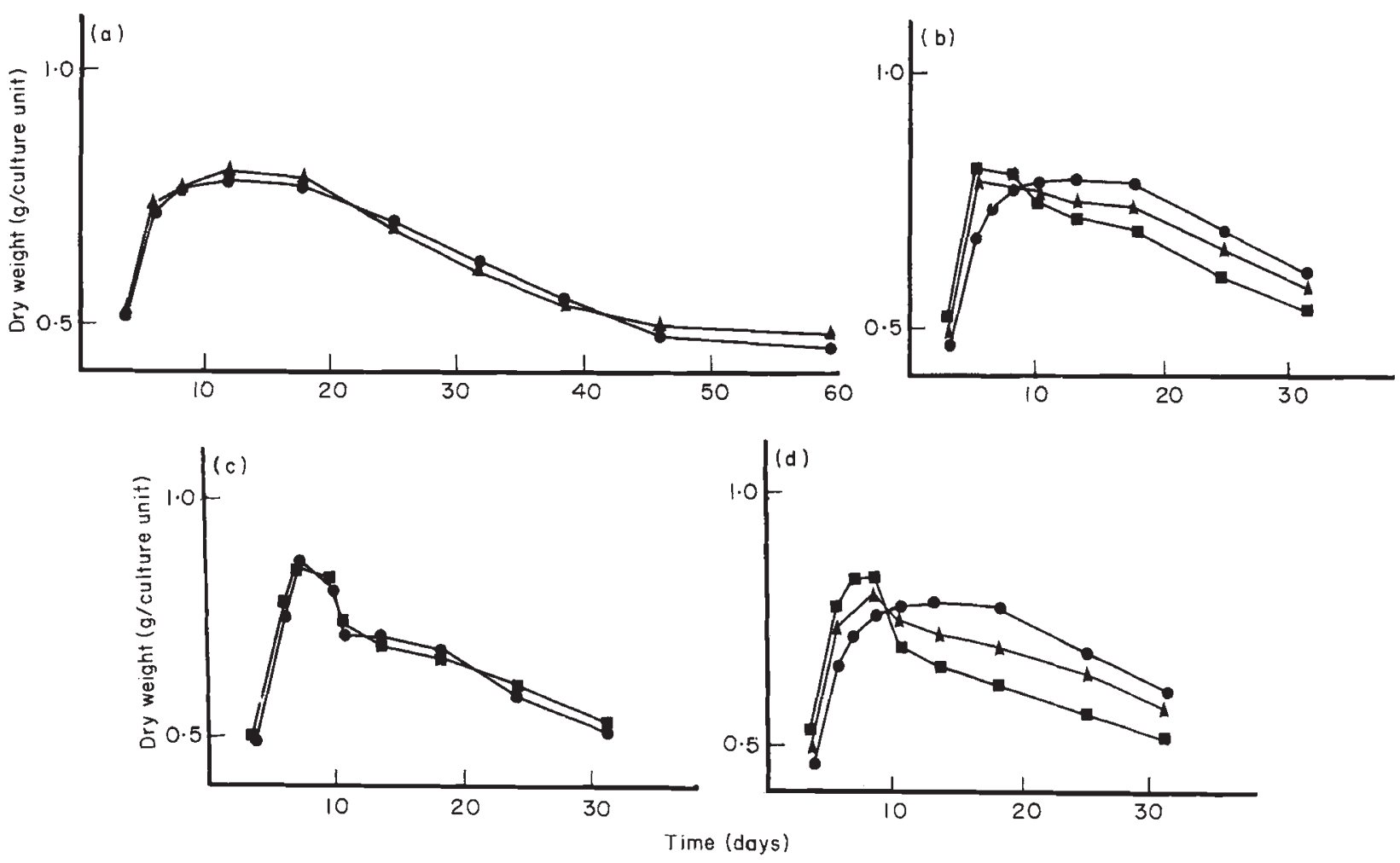

Fig. 2 Time course of dry weight production of Podospora cultures grown in liquid medium. (a) Wild-type (circle), modA modB (triangle). (b) (+/-) Heterokaryotic strains: wild-type (square), $\bmod A \bmod B c(A) d(O) \operatorname{e}(O) \mathrm{rV}(\mathrm{circle})$ or $\bmod A \operatorname{modB} c(A)$ $d(O) e(O) r V 1$ (triangle). (c) $\bmod F$ (square) and triple mutant modA modB modF (circle). (d) Mutant modE (square) and triple mutants $\bmod E \bmod A \bmod B$ of genotypes $c(A) d(O) e(O) r V($ circle $)$ or $c(A) d(A) e(A) r V$ (triangle). 
development was identical to that of homokaryotic + or - strains. However, the cell death specific to a $+/-$ interaction was found in $c-v \bmod A \bmod B$ genotypes permissive for protoperithecial and perithecial development. Two examples of the differential action of $c-v$ genotypes on the cell life span of $+1-$ cells are given in Fig. 2b. Thus, the cell death that results from the interaction of the mating type alleles was dependent on the $c$ - $v$ and mod genes.

Homokaryotic mutant strains $(+$ or -$)$ with reduced cell life spans have already been described. The first mutant, $\bmod F$, produces a high density of protoperithecia that are unable to develop into perithecia following fertilization, presumably because hyphal cells do not survive exhaustion of the culture medium (Durrens, 1984). This interpretation is supported by the results presented here. Indeed, it is shown (Table 1, Expt C) that the modF mutant does not support the development of $\bmod A \bmod B$ perithecia. To analyse a possible effect of $\bmod A \bmod B$ mutations on the reduced life span of $\bmod F$ cells, a triple mutant $\bmod F \bmod A \bmod B$ was constructed. Cell survival in $\bmod F \bmod A \bmod B$ cultures (Fig. 2c) was identical to cell survival in $\bmod F$ cultures, which mdicates that the premature cell death, specific to the $\bmod F$ mutation, is independent of the action of the $\bmod A$ and $\bmod B$ genes.

A second mutant defective in cell survival $(\bmod E)$ was named 'perithecial' because it produced protoperithecia which developed into perithecia without fertilization when cultured on solid medium (Durrens, 1983). This spontaneous development resulted in sterile perithecia (free of ascospores) similar in size to fertile perithecia. An investigation of $\bmod E+/ \bmod E$ heterokaryotic strains showed that $\bmod E$ was not a perithecium-autonomous mutation, which indicates that the hyphal cells were the focus of, or at least involved in, modE gene action (Durrens, 1983). Present results show (Table 1, Expt D) that the $\operatorname{modE}$ mutant supports the development of $\bmod A \bmod B$ perithecia, which contrasts with the $\bmod F$ mutant (Table 1, Expt C). Triple mutants $\bmod E \bmod A \bmod B$ with different alleles at the $c-v$ loci were constructed. They showed a complete or partial suppression of the shorter life span when cultured in liquid medium, resulting from the $\bmod E$ mutation that depended on the $c-v$ genotype (Fig. $2 \mathrm{~d}$ ). This indicates that the $c-v$, $\bmod A$ and $\bmod B$ genes are involved in cell death resulting from the action of $\bmod E$ mutation. Hence, it is shown that the two genetic conditions that are necessary for perithecium development in solid culture medium (i.e. the $+1-$ interaction between protoperithecia and microconidia and the modF mutation), cause premature death of hyphal cells in liquid medium cultures that entirely depends on the action of $\bmod$ and $c-v$ genes.

In conclusion, it appears from the study of $\operatorname{modF}$ mutants that the development of perithecia in Podospora cultures is possible only when hyphal cells are initially alive as a consequence of being previously shifted from growth to quiescence prior to the exhaustion of the culture medium. The second condition for perithecium development (as exemplified by the study of the $+/-$ heterokaryons and the $\bmod E$ mutants) is the induction of a process leading to the death of hyphal cells. This process is controlled by the action of $\bmod A, \bmod B$ and $c-v$ genes.

\section{Discussion}

The results presented here show that the $\bmod$ and $c-v$ genes are involved in the growth of all the aerial parts of mycelia, i.e. proto- and perithecia as already reported (Boucherie \& Bernet, 1980), also aerial hyphae and the apical cells of leading hyphae when these are forced to grow outside the growth substrate. The $\bmod$ and $c-v$ genes of Podospora are therefore involved in an important and significant process in the development of fungi; namely the production of aerial derivatives that are used for the dissemination of the asexual and sexual products of mycelium.

This study confirms that the inhibitory action of mod mutations on protoperithecium and perithecium development is a secondary effect. Indeed, it is shown that the mod genes are responsible for the premature death of hyphal cells in the absence of protoperithecia and perithecia (liquid cultures) that is modulated by the action of $c-v$ genes. This death is also induced in response to conditions that result in perithecium development: $+1-$ mating-type allele interaction or perithecial $\bmod E$ mutation. It thus appears that the premature cell death resulting from the action of $\bmod A, \bmod B$ and $c-v$ genes, seen in liquid medium cultures, is identical to the cell death associated with the development of perithecia in fertile solid medium cultures. Previous results showed that protoplasmic incompatibility is associated with the occurrence of several catabolic activities or with large increases in their levels (Bégueret \& Bernet, 1973; Boucherie \& Bernet, 1978). Protoplasmic incompatibility may therefore be the unregulated expression of cell death (present work). This is consistent with the idea that the vegetative cells of fertile Podospora cultures are converted into a source of nutrients for developing perithecia by the degradative activities that are controlled by $c-v$ and mod genes. Accordingly, protoplasmic incompatibility is thought to result from random mutations in the genes that control these catabolic ac- 
tivities. Hence, protoplasmic incompatibility could be viewed as a passive consequence of the separate evolution of the Podospora wild-type isolates and not, as previously supposed (Esser, 1971), the original cause of their divergences.

Studies of the genetic control of protoplasmic incompatibility (Bégueret, 1969; Bernet et al., 1973), led to the presumption that the $c-v$ gene products were proteins that give rise to specific interactions. Furthermore, an investigation of controlled anastomoses that involve individual hyphae showed that the $c$ and $v$ gene products were diffusible in hyphae, in contrast to the products of genes $d, e, r, \bmod A$ and $\bmod B$ (Bernet, 1965; Labarère et al., 1974; Bernet et al., 1973). The products of genes $d, e, r$ and $\bmod B$ are believed to be associated with the plasma membrane (Asselineau et al., 1981). Products of the $c$ and $v$ genes may therefore be analogous to peptide hormones and those of the $d, e$ and $r$ genes to their receptors. Accordingly, the death of hyphal cells in the large areas surrounding individual developing perithecia (Bernet, 1965) may be due to the actions of genes $c$ and $v$ that give rise to products that diffuse far from the perithecia into the hyphal cells. The production of fertile perithecia consequent to $c(A) / d(A) e(A)$ or $V 1 / r$ interactions in strains $d(A)$ $e(A)$ or $V 1 R$ (Table 1, Expts $\mathrm{G}$ and $\mathrm{L}$ ), and not in strains $c(A)$ or $\operatorname{Vr}$ (Table 1, Expts $\mathrm{H}$ and $\mathrm{K}$ ), confirms that $c$ and $v$ are the genes that give rise to the products that diffuse from the perithecia to the hyphal cells.

Previous work, based upon the study of several wildtype alleles (most of the alleles known at the $c, d, e, r$ and $v$ loci) or mutant alleles $(c, d, e, f, g, h$ and $l$ loci), has shown that the female fertility of $\bmod A \bmod B$ strains is dependent on the $c-v$ genes (Boucherie et al., 1976; Boucherie \& Bernet, 1980). This study indicates, in particular, that each of the $c e$ (or $c d$ ) gene combinations investigated display a distinct quantitative action (negative, null or positive according to the source of the $c, d$ and $e$ genes), which is additive to the action of each of the three non-lethal $r v$ gene combinations $(r, R v$ or $r V 1)$ in the determination of the relative female fertility of a $\bmod A \bmod B$ strain. In contrast (Boucherie, 1979), the female fertility of wildtype strains $(\bmod A+\bmod B+)$ appears to be only weakly modified by variation of the $c-v$ genotype. Presumably, the reduced basic female fertility of the $\bmod A \bmod B$ strain and its extreme susceptibility to various extrinsic and intrinsic factors (Boucherie \& Bernet, 1980) may account for the amplification in this genotype of the individual action of each $c / d, c / e$ or $r / v$ gene interaction. Podospora contains many potential loci for non-allelic protoplasmic incompatibility in addition to the nine $c-v$ loci investigated so far (Delettre \& Bernet, 1976). Hence, the $c-v$ genes may be part of a multigenic system that controls perithecium development (i.e. cell death according to the present results) via the action of multiple specific geneto-gene interactions on two common regulatory genes. Accordingly, if the $c-v$ genes are genes of minor effect in the control of their presumptive genuine function (cell death), they manifest themselves as major genes in their deviant expression because each of any of the five $C / D \ldots F / G \ldots$ or $R / V$ interactions can result in protoplasmic incompatibility. Postulated relationships

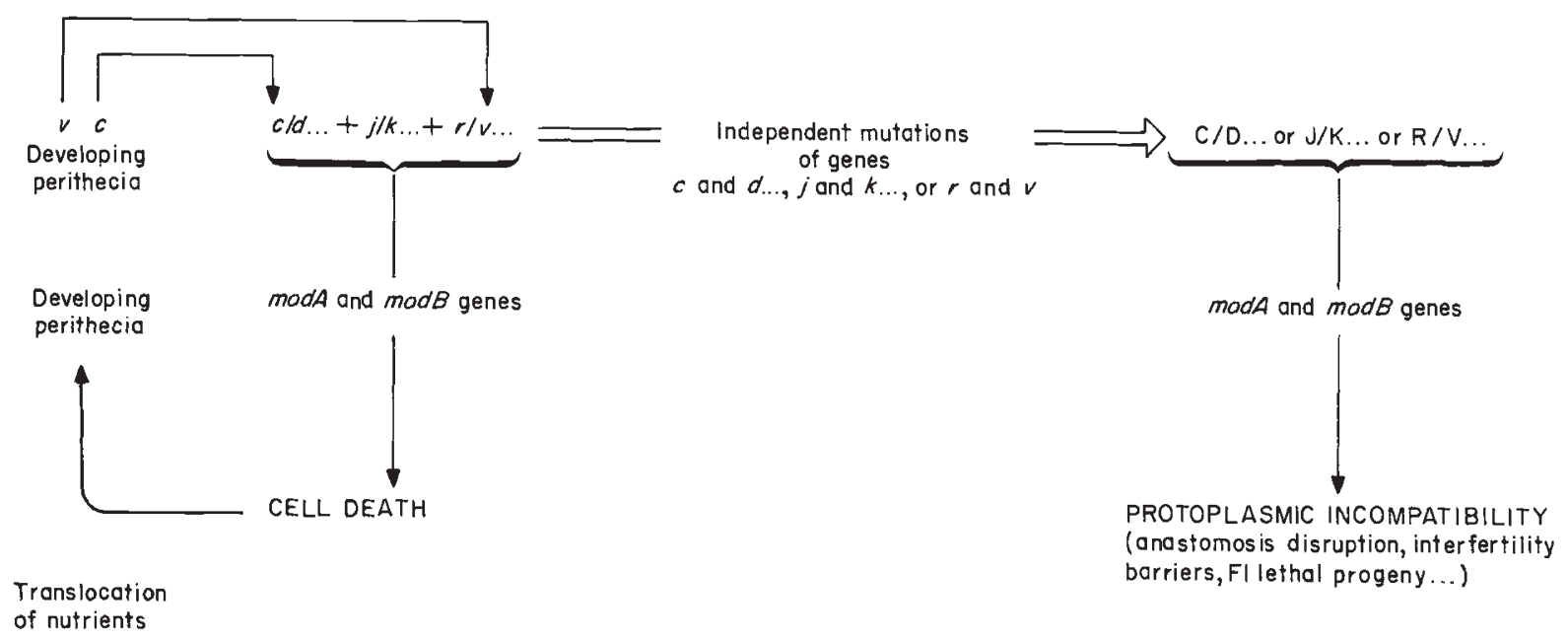

Fig. 3 Relationships between the action of the $c-v$ and mod genes in cell death and protoplasmic incompatibility (explanations in the text). 
between cell death and protoplasmic incompatibility are summarized in Fig. 3.

Cloning of $c$ and $e$ genes is achieved (J. Bégueret, personal communication) and that of $d, r, v, \bmod A$ and $\bmod B$ is expected. It is therefore hoped that analysis of these genes confirms their function in cell death and provides a model which attempts to define the action of the individual genes of polygenic systems.

\section{References}

AMES, L. M. 1934. Hermaphroditism involving self-sterility and cross-fertility in the ascomycete Pleurage anserina. Mycologia, 26, 392-414.

ASSELINEAU, D., BERNET, J. AND LABARÈRE, J. 1981. Protoplasmic incompatibility in Podospora anserina: possible involvement of the plasma membrane in the trigger mechanism. $J$. Gen. Microbiol., 125, 139-146.

BARREAU, C. 1983. Thesis, University of Bordeaux 2.

BEISSON-SCHECROUN, J. 1962. Incompatibilité cellulaire et interactions nucléocytoplasmiques dans les phénomènes de barrage chez le Podospora anserina. Ann. Gen., 4, $1-50$.

BÉGUERET, J. 1969. Sur le mécanisme des réactions d'incompatibilité chez le Podospora anserina. C.R. Acad. Sci. Paris D, 269, 458-461.

Bégueret, J. AND Bernet, J. 1973. Proteolytic enzymes and protoplasmic incompatibility in the fungus Podospora anserina. Nature New Biol., 243, 94-98.

BELCOUR, L. 1985. Thesis, University of Paris 11.

BELCOUR, L. AND BERNET, J. 1969. Sur la mise en évidence d'un gène dont la mutation supprime spécifiquement certaines manifestations d'incompatibilité chez le Podospora anserina. C.R. Acad. Sci. Paris D, 269, 712-714.

BERNET, J. 1965. Mode d'action des gènes de barrage et relation entre l'incompatibilité cellulaire et l'incompatibilité sexuelle chez le Podospora anserina. Ann. Sci. Nat. Bot., 6, 611-768.

BERNET, J. 1967. Systèmes d'incompatibilité chez le Podospora anserina. C.R. Acad. Sci. Paris D, 265, 1536-1539.

BERNET, J. 1971. Sur un cas de suppression de l'incompatibilité cellulaire chez le Podospora anserina. C.R. Acad. Sci. Paris D, 273, 1120-1122.

BERnET, J. 1986. Podospora mutations reducing cell survival following nutrient exhaustion. Curr. Microbiol., 14, 133-136.

BERNET, J. 1988. Podospora growth control mutations inhibit apical cell anastomosis and protoperithecium formation. Exptl Mycol., 12, 217-222.

BERNET, J., BEGUERET, J. AND LABARÉRE, J. 1973. Incompatibility in the fungus Podospora anserina: are the mutations abolishing the incompatibility reaction ribosomal mutations? Molec. Gen. Genet., 124, 35-50.

BERNET, J., ESSER, K., MARCOU, D. AND SCHECROUN, J. 1960. Sur la structure génétique de l'espèce Podospora anserina et sur l'intérêt de cette structure pour des recherches de génétique. C.R. Acad. Sci., 250, 2053-2055.

BOUCHERIE, H. 1979. Thesis, University of Bordeaux 2 .
BOUCHERIE, H., BÉGUERET, J. AND BERNET, J. 1976. The molecular mechanism of protoplasmic incompatibility and its relationship to the formation of protoperithecia in the fungus Podospora anserina. J. Gen. Microbiol., 92, 59-66.

BOUCHERIE, H. AND BERNET, J. 1974. Protoplasmic incompatibility and female organ formation in Podospora anserina: properties of mutations abolishing both processes. Molec. Gen. Genet., 135, 163-174.

BOUCHERIE, H. AND BERNET, J. 1978. Protoplasmic incompatibility and self-lysis in Podospora anserina: enzymes associated with cell destruction. Can. J. Bot., 56, 2171-2176.

BOUCHERIE, H. AND BERNET, J. 1980. Protoplasmic incompatibility in Podospora anserina: a possible function for incompatibility genes. Genetics, 96, 399-411.

BOUCHERIE, H., DUPONT, C. H. AND BERNET, J. 1981. Polypeptide synthesis during protoplasmic incompatibility in the fungus Podospora anserina. Biochim. Biophys. Acta, 653, 18-26.

CATEN, C. E. 1972. Vegetative incompatibility and cytoplasmic infection in fungi. J. Gen. Microbiol, 72, 221-229.

DELETTRE, Y. M. AND BERNET, J. 1976. Regulation of proteolytic enzymes in Podospora anserina: selection and properties of self-lysis mutant strains. Molec. Gen. Genet., 144, 191-197.

DURRENS, P. 1983. Podospora mutant defective in glucosedependent growth control. J. Bacteriol., 154, 702-707.

DURrens, P. 1984. Podospora anserina mutations reducing cell survival under glucose starvation. Exptl Mycol., 6, 216-224.

DURRENS, P. AND BERNET, J. 1982. Podospora anserina mutations inhibiting several developmental alternatives and growth renewal. Curr. Genet., 5, 181-185.

DURRENS, P. AND BERNET, J. 1985. Temporal action of mutations inhibiting the accomplishment of quiescence or disrupting development in the fungus Podospora anserina. Genetics, 109, 37-47.

ESSER, K. 1971. Breeding systems in fungi and their significance for genetic recombination. Mol. Gen. Genet., 110, 86-100.

ESSER, K. 1974. Podospora anserina. In: King, R. C. (ed.), Handbook of Genetics. Plenum Press, New York, pp. 531-551.

ESSER, K. AND BLAICH, R. 1973. Heterogenic incompatibility in plants and animals. Adv. Genet., 17, 105-152.

LABARÉRE, J., BÉGUERET, J. AND BERNET, J. 1974. Incompatibility in Podospora anserina: comparative properties of the antagonistic cytoplasmic factors of a non-allelic system. $J$. Bacteriol., 120, 854-860.

LABARÈre, J. AND Bernet, J. 1979. Protoplasmic incompatibility in Podospora anserina: a possible role for its associated proteolytic activity. Genetics, 93, 525-537.

RIZET, G. AND ENGELMAN, C. 1949. Contribution à l'étude d'un ascomycète tétrasproré: Podospora anserina. Rev. Cytol. Biol. Vég., 11, 201-304.

RIZET, G. AND ESSER, K. 1953. Sur les phénomènes d'incompatibilité entre souches d'origine différentes chez Podospora anserina. C.R. Acad. Sci. Paris, 237, 760-761.

RIZET, G. AND SCHECROUN, J. 1959. Sur les facteurs associés au couple de gènes $S$-s chez le Podospora anserina. C.R. Acad. Sci. Paris, 249, 2392-2394. 